\title{
Comment on "Is ionizing radiation a risk factor for anxiety in employees?"
}

\author{
Xu zhang ${ }^{1} \odot$, Tingting Li1 $\odot$, Baohong Xue ${ }^{1 *}$ (])
}

Dear Editor,

We read with great interest the study by Asli Kurtar Mansiroglu et al. ${ }^{1}$, in which they demonstrated that radiation is likely to be a risk factor for anxiety among hospital staff, although, in our opinion, the author should combine more clinical cases to confirm this view.

First, although the two groups of research objects selected by the researchers come from the same working environment, there are still some differences, which will affect the accuracy of the research results; the author should choose a more similar working environment to reduce the interference of relevant influencing factors and research conclusions.
Second, the author's conclusion is only to prove that radiation is one of the risk factors affecting employee anxiety. However, the further influencing mechanism is not determined.

\section{REFERENCE}

1. Mansiroglu AK, Erer M, Coșgun M, Sincer I, Güneș $Y$. Is ionizing radiation a risk factor for anxiety in employees? Rev Assoc Med Bras (1992). 2020;66(12):1685-9. https:// doi.org/10.1590/1806-9282.66.12.1685 